\title{
Platelet Antibodies of the IgM Class in Immune Thrombocytopenic Purpura
}

Douglas B. Cines, Susan B. Wilson, Ann Tomaski, and Alan D. Schreiber

Hematology-Oncology Section, Departments of Medicine and Pathology, Hospital of the University of Pennsylvania,

Philadelphia, Pennsylvania 19104

\begin{abstract}
The clinical course and response to therapy of patients with immune thrombocytopenic purpura (ITP) are not completely determined by the level of IgG present on the platelet surface. It is possible that antibodies of other immunoglobulin classes also play a role in platelet destruction in some of these patients. Therefore, we studied 175 patients with ITP for the presence of IgM anti-platelet antibodies using radiolabeled polyclonal or monoclonal anti-IgM. We observed that $57 \%$ of patients with clinical ITP had increased levels of IgM on their platelets, compared with normal controls and patients with thrombocytopenia who did not have ITP $(<10 \%),(P<0.01)$. We obtained similar results using either radiolabeled polyclonal or monoclonal anti-IgM, reagents whose integrity was first characterized using erythrocytes coated with defined amounts of IgM antibody. Among patients with increased platelet-IgM there was a significant correlation both with the presence of increased platelet$\mathrm{C3}$ as well as the amount of platelet-C3 $(P<0.01, r=0.53)$. We demonstrated the presence of warm-reacting IgM antiplatelet antibodies in the plasma of two of these patients who were further studied. The isolated IgM fraction from these two plasmas was able to activate complement and place ${ }^{3} \mathrm{H}-\mathrm{C} 3$ on normal platelets. These studies demonstrate the presence of warm-reacting IgM anti-platelet antibodies in some patients with ITP. They suggest that the binding of complement to platelets by IgM antibodies may initiate platelet clearance as well as enhance the effect of IgG antibodies in ITP.
\end{abstract}

\section{Introduction}

Thrombocytopenia in patients with immune thrombocytopenic purpura (ITP) ${ }^{1}$ is caused by the accelerated removal of immunoglobulin-coated platelets from the circulation. The most important ligand on the platelet surface recognized by tissue macrophages is IgG, either in the form of antibody or immune complexes. It is less clear, however, whether the measured amount of IgG on the platelet surface, by itself, determines either the extent of the platelet destruction or the magnitude of the thrombocytopenia (1-6). For example, increased amounts

\section{Address correspondence to Dr. Cines. \\ Received for publication 21 May 1984 and in revised form 15 October 1984}

1. Abbreviations used in this paper: ITP, immune thrombocytopenic purpura; NSP, $N$-succinimidyl $\left(2,3-{ }^{3} \mathrm{H}\right)$ propionate; PA, platelet associated.

J. Clin. Invest.

(C) The American Society for Clinical Investigation, Inc.

$0021-9738 / 85 / 04 / 1183 / 08 \$ 1.00$

Volume 75, April 1985, 1183-1190 of platelet-bound IgG have been detected in some patients whose thrombocytopenia is not believed to be mediated by antiplatelet antibodies (7-10). Furthermore, increased plateletIgG is detected in occasional patients who have a normal platelet count $(7,8)$. These data suggest that factors other than the amount of IgG on the platelet influence the recognition and removal of ITP platelets.

One such factor that might accelerate platelet clearance is C3, the third component of complement. In patients with immune hemolytic anemia, for example, the presence of cellbound $\mathrm{C} 3$ influences the rate and site of erythrocyte clearance (11). Several investigators have noted increased amounts of C3 on the platelets of some patients with ITP. This increase in platelet-C3 is generally associated with the presence of increased amounts of platelet-IgG (12-15). However, we have observed that some ITP patients have increased levels of platelet-associated (PA)-C3 with normal levels of PA-IgG (13). In these cases, the deposition of $\mathrm{C} 3$ could result from the presence of anti-platelet antibodies of the IgM class that are known to activate complement more efficiently than most IgG antibodies. Indeed, several investigators have recently observed increased amounts of IgM on the platelets of some patients with ITP (15-22). Therefore, we sought to determine if complement-fixing IgM anti-platelet antibodies are, in fact, demonstrable in ITP and could account for the presence of $\mathrm{C} 3$ on the platelets of some of these patients. We also sought to determine whether the presence of IgM antibody might help to explain some of the variation in the severity of ITP.

\section{Methods}

Patients. We initially studied 127 consecutive patients with idiopathic thrombocytopenic purpura using previously reported criteria for diagnosis (13). Platelet counts in these patients ranged from 5,000 to $258,000 / \mathrm{mm}^{3}\left(96,000 \pm 77,000 / \mathrm{mm}^{3}\right.$, mean $\left.\pm 2 \mathrm{SD}\right) .104$ patients were thrombocytopenic (platelet count $<150,000 / \mathrm{mm}^{3}$ ) while 23 were in clinical remission at the time of study. 99 patients were untreated, while 28 were taking corticosteroids, eight had undergone splenectomy, two were receiving intraveneous gammaglobulin, and one was receiving infusions of vinblastine. We also studied the platelets obtained from 78 normal healthy volunteers and 32 thrombocytopenic patients who did not have a clinical diagnosis of ITP. The causes of thrombocytopenia in these patients included hypersplenism (3), marrow suppression from chemotherapy (1), drug-induced thrombocytopenia (6), hereditary thrombocytopenia (2), chronic lymphocytic leukemia (3), marrow involvement with another malignant (5) or a nonmalignant process (4), marrow hypoplasia (4), disseminated intravascular coagulation (3), and sepsis (1). The mean platelet count in this thrombocytopenic control population was $53,000 \pm 33,000 / \mathrm{mm}^{3}$ (mean $\pm 2 \mathrm{SD}$ ). To compare the binding of monoclonal anti-IgM and polyclonal anti-IgM (see below), we studied an additional 48 patients with untreated ITP, an additional 35 normal controls, and an additional 12 patients who were thrombocytopenic but did not have a clinical diagnosis of ITP.

Measurement of platelet-bound immunoglobulin and complement. 
Rabbit antiserum against human IgG (gamma chain) was obtained from Calbiochem-Behring Corp., La Jolla, CA. The IgG fraction of rabbit antiserum against human $\operatorname{IgM}(\mu$ chain) or $\mathrm{C} 3$ were obtained from Atlantic Antibodies, Scarborough, ME. The IgG fraction was isolated from anti-IgG antisera and normal rabbit serum by affinity chromatography using anti-rabbit IgG agarose (Miles Laboratories, Elkhart, IN). Murine monoclonal anti-human IgM ( $\mu$ chain) was obtained from Bethesda Research Laboratories, Gaitersburg, MD. Each IgG fraction was radiolabeled with ${ }^{125} \mathrm{I}-\mathrm{Na}$ (New England Nuclear, Boston, MA) to a specific activity of $1.3-2.1 \times 10^{5} \mathrm{cpm} / \mu \mathrm{g}$ protein (23).

We determined the level of platelet-bound IgG, IgM, and C3 as well as plasma $\mathrm{IgG}$ and IgM anti-platelet antibody activity using the radiolabeled antiglobulin test (13). In this assay, the level of plateletbound immunoglobulin or $\mathrm{C} 3$ is determined by the extent of binding of the specific radiolabeled antiglobulin reagent. Briefly, $1 \times 10^{8}$ washed platelets from patients or normal donors were incubated with an aliquot of each labeled ligand for $45 \mathrm{~min}$ at $37^{\circ} \mathrm{C}$, washed four times, and the platelet-bound radioactivity determined. In the indirect test, 1 $\times 10^{8}$ washed normal platelets were first incubated with normal or patient plasma in $0.01 \mathrm{M}$ EDTA buffer, washed four times, and then incubated with each labeled ligand. Assays on patient platelets were generally performed using $\sim 1 \mu \mathrm{g}$ of each heterologous antibody, monoclonal anti- $\mu$ chain antibody, or similarly labeled normal rabbit $\mathrm{IgG}$, per $10^{8}$ platelets. Specific binding of rabbit $\mathrm{IgG}$ anti-IgM to platelets (i.e., that portion of total binding due solely to the interaction of the anti-IgM antibody with platelet-bound IgM) was first assessed by preincubating platelets with a 100-fold excess of normal rabbit IgG before incubation with ${ }^{125} \mathrm{I}-\mathrm{IgG}$ anti-IgM. In addition, we compared the binding to platelets of labeled IgG anti-IgM and labeled normal rabbit IgG not having antibody activity. In experiments in which we measured the binding of monoclonal IgG anti-IgM to platelets, we used the radiolabeled IgG fraction of the parent mouse myeloma line (P3) as the nonimmune control. Binding of ${ }^{125} \mathrm{I}-\mathrm{P} 3$ to all platelets was $<0.05 \%$ of the total available radioactivity in all experiments. The extent of binding of each antiglobulin preparation to platelets is expressed as a percentage of the total radioactivity to which the platelet was exposed according to the formula: $\%$ binding $=$ (platelet-associated $\mathrm{cpm}-$ test tube $\mathrm{cpm}) /($ total $\mathrm{cpm}-$ test tube $\mathrm{cpm}) \times 100$.

Binding of ${ }^{125}$ I anti-IgM to antibody-coated erythrocytes. We first determined the optimal conditions for detecting cell-bound IgM by studying the binding of ${ }^{125}$ I anti-IgM to IgM-coated erythrocytes. The IgM fraction of anti-erythrocyte blood group A substance was prepared from human antiserum by gel filtration chromatography (13) and quantitated as protein (24). We then radiolabeled the IgM preparation with tritium using $N$-succinimidyl $\left(2,3-{ }^{3} \mathrm{H}\right.$ )propionate (NSP) (Amersham Corp., Arlington Heights, IL). To tritiate this protein, the IgM preparation was dialyzed against $0.1 \mathrm{M}$ borate buffer, $\mathrm{pH}$ 8.4. The NSP was evaporated under nitrogen in a glass tube at $0^{\circ} \mathrm{C}$ just before use. The IgM was then added to the NSP for $15 \mathrm{~min}$ at $0^{\circ} \mathrm{C}$. The unreacted NSP was then inactivated by the addition of 2 vol of $0.5 \mathrm{M}$ glycine for $5 \mathrm{~min}$ at $0^{\circ} \mathrm{C}$. We separated the radiolabeled IgM from residual free NSP by applying the protein to a Sephadex G-50 column equilibrated with $0.0035 \mathrm{M}$ phosphate buffer containing $0.12 \mathrm{M} \mathrm{KCl}$, pH 7.4. $1 / 2-\mathrm{ml}$ fractions were collected and assayed for ${ }^{3} \mathrm{H}$ in a scintillation counter (Beckman Instruments, Inc., Fullerton, CA). The resultant ${ }^{3} \mathrm{H}$-labeled IgM had a specific activity of $3-5 \times 10^{3} \mathrm{cpm} / \mu \mathrm{g}$ protein. We examined whether the process of trace labeling altered the antibody activity of the IgM anti-A antibody. Type A erythrocytes were incubated with varying concentrations of labeled and unlabeled IgM anti-A and the subsequent binding of ${ }^{125} \mathrm{I}-\mathrm{IgG}$ anti-human IgM was determined. Using this technique, we found that the ${ }^{3} \mathrm{H}$-labeled IgM anti-A had essentially identical antibody activity as unlabeled IgM anti-A.

$1 \mathrm{ml}$ of washed erythrocytes $\left(1 \times 10^{8} / \mathrm{ml}\right)$ prepared from normal type $A$ and type $B$ donors was incubated with varying concentrations of ${ }^{3} \mathrm{H}$-IgM anti-A at $37^{\circ} \mathrm{C}$ for $30 \mathrm{~min}$ and washed four times in isotonic veronal-buffered saline, $\mathrm{pH}$ 7.4. Erythrocyte membranes were then prepared in hypotonic buffer (25), solubilized in Protosol (New England Nuclear), and counted for radioactive emission in a scintillation counter (Beckman Instruments, Inc.). Specific binding of ${ }^{3} \mathrm{H}$-IgM antiA to type A erythrocytes was determined by subtracting the amount of binding of the labeled ligand to type B erythrocytes.

We then determined the binding of ${ }^{125}$ I anti-IgM to these erythrocytes sensitized with IgM antibody. To perform this study, type A and type B erythrocytes were first sensitized with varying concentrations of ${ }^{3} \mathrm{H}$ IgM anti-IgA, washed and incubated with ${ }^{125}$ I-polyclonal or monoclonal anti-human IgM, which contained 1-2 $\mu$ g of labeled protein, for 45 $\min$ at $37^{\circ} \mathrm{C}$; the labeled cells were then washed four times and the erythrocyte-associated radioactivity determined. Specific binding of this antibody (i.e., binding due only to the interaction of anti-IgM with IgM anti-A) was defined in two ways. First, IgM-sensitized type A erythrocytes were incubated with varying concentrations (1-50-fold molar excess) of unlabeled rabbit IgG anti-IgM or normal rabbit IgG for $30 \mathrm{~min}$ at $37^{\circ} \mathrm{C}$ before the addition of ${ }^{125} \mathrm{I}-\mathrm{IgG}$ anti-IgM, and the erythrocyte-associated radioactivity determined. Specific binding was defined as that portion of the binding of the labeled antiglobulin reagent that could be inhibited by a 50-M excess of unlabeled antiIgM, but not by a similar concentration of normal rabbit IgG. Second, we determined the difference in the binding of ${ }^{125}$ I anti-IgM to IgMsensitized type A and type B erythrocytes. This difference is a measure of specific binding of labeled anti-IgM because IgM anti-A did not show any measurable specific binding to type B erythrocytes (see Results). In parallel studies we also determined the extent of crossreactivity of ${ }^{125}$ I anti-IgM with cell-bound IgG by measuring its binding to type A erythrocytes that were sensitized with equivalent amounts of ${ }^{3} \mathrm{H}-\mathrm{IgG}$ and ${ }^{3} \mathrm{H}-\mathrm{IgM}$ anti-A. In order to quantitate the amount of labeled anti-IgM that binds to cell-bound IgM at saturation, type A blood cells that were sensitized with a single concentration of ${ }^{3} \mathrm{H}$-IgM anti-A were then incubated with varying concentrations of ${ }^{125}$ I antiIgM and the cell-associated radioactivity determined. We also compared the binding of the labeled polyclonal and monoclonal anti-IgM reagents to erythrocytes that were sensitized with varying concentrations of ${ }^{3} \mathrm{H}$ IgM anti-A.

Preparation of human C3. C3 was isolated from human plasma by the method of Hammer et al. (26) with slight modifications. A 1,200$\mathrm{ml}$ pool of fresh frozen plasma was obtained from two donors (Community Blood Bank, Philadelphia, PA) treated with $50 \mathrm{mM}$ epsilonaminocaproic acid and $1 \mathrm{mM}$ phenylmethanesulfonyl fluoride, and precipitated with $5 \%$ polyethylene glycol. The supernatant was applied to a Sepharose L-lysine column to remove plasminogen. 500 $\mathrm{ml}$ of this plasminogen-free plasma was dialyzed and fractionated on a DEAE Sephacel column $(5 \times 100 \mathrm{~cm})$ using a linear salt gradient (1.3-10.5 mmho conductivity). Fractions were analyzed for complement and immunoglobulin proteins by effective molecule titration and Ouchterlony analysis. Trace amounts of IgG, IgA, and C5 were removed by hydroxylapatite chromatography as assessed by Ouchterlony analysis and effective molecule titration of C5. The concentration of the purified $C 3$ was $1.25 \mathrm{mg} / \mathrm{ml}$ by radial immunodiffusion and 16,000 hemolytically effective units per milliliter by effective molecule titration. This is similar to the data we observed for the $\mathrm{C} 3$ in normal plasma before isolation where $\mathrm{C} 3(1 \mathrm{mg} / \mathrm{ml})$ had a specific hemolytic activity of 10,000 effective units per milliliter. The resultant protein was analyzed using SDS-7.5\% polyacrylamide disc gels which were then stained for protein with Coomassie Blue. The $\mathrm{C} 3$ preparation consisted of a single protein band with an apparent molecular weight of 230,000, which produced the characteristic $\alpha$ - and $\beta$-chains upon reduction in 2-mercaptoethanol. The eluted protein from alkaline disc gels run in parallel was shown to be $\mathrm{C} 3$ by Ouchterlony analysis.

The purified $\mathrm{C} 3$ was then radiolabeled with ${ }^{3} \mathrm{H}$ using NSP as above. After radiolabeling, unbound NSP was separated from ${ }^{3} \mathrm{H}-\mathrm{C} 3$ using Sephadex G-50. The labeled C3 had a specific activity of $\sim 1.0 \times 10^{4}$ $\mathrm{cpm} / \mu \mathrm{g} \mathrm{C} 3$ and retained $85-95 \%$ of its initial hemolytic activity when assayed by effective molecule titration $(11,27)$. When determining the number of $\mathrm{C} 3$ molecules deposited on the platelet surface, we used a 
mixture of labeled and unlabeled C3. Between 10 and $40 \%$ of the total available $\mathrm{C} 3$ in these experiments was tritiated.

Statistics. All statistical analyses, including $P$ values determined by the $t$ test and linear regression analyses, were performed using the Hewlett-Packard computer (model HP86B, Hewlett-Packard Co., Corvallis, $\mathrm{OR})$.

\section{Results}

The purpose of this study was to measure the amount of IgM on platelets from patients with ITP and to compare these results with the amount of IgM on normal platelets using radiolabeled antiglobulin reagents. In order to address this question, we first needed to determine the extent to which the binding of labeled anti-IgM depended upon the presence and amount of cell-bound IgM, the extent to which the labeled anti-IgM cross-reacted with cell-bound IgG, and the approximate amount of anti-IgM that bound to each molecule of cellbound IgM at saturation. Because the amount of IgM on platelets is unknown, we first characterized the binding of radiolabeled anti-IgM to human erythrocytes that were sensitized with known amounts of IgM antibody.

The schema we used to answer these questions is outlined in Fig. 1. In reaction 1, type A or type B (not shown) erythrocytes were sensitized with ${ }^{3} \mathrm{H}$-labeled IgG or IgM fractions of anti-A antisera. By measuring the resultant cell-bound radioactivity, we were able to prepare erythrocytes sensitized with known amounts of human IgG or IgM. In reaction 2, ${ }^{125}$ I-labeled rabbit or murine IgG anti-human IgM was then added to these cells to determine the extent of its binding to cell-bound IgG or IgM. In these studies we employed a range of concentrations of IgG and IgM anti-erythrocyte antibodies,

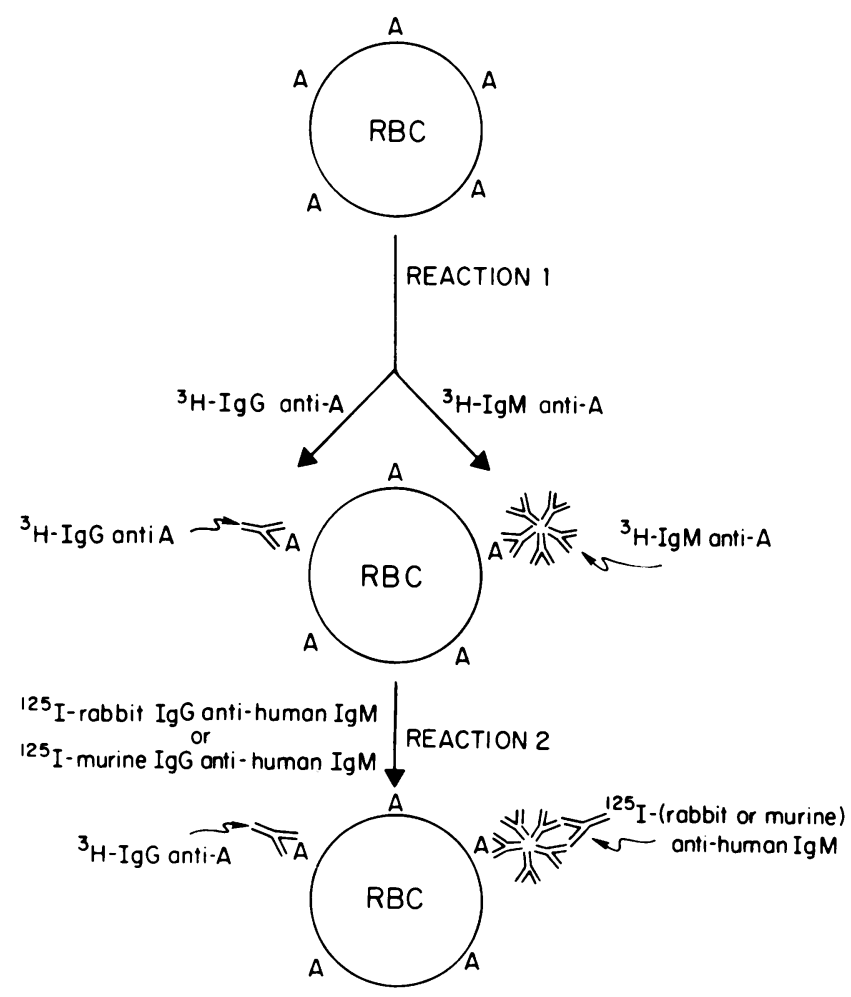

Figure 1. Reaction sequence to assess the binding of radiolabeled anti-IgM to IgM-coated erythrocytes (RBC). which we subsequently determined were comparable to the amounts of each protein present on normal and ITP platelets.

Binding of ${ }^{125}$ I anti-IgM to IgM-coated erythrocytes. We first examined the binding of labeled IgM anti-A to type A and type B human erythrocytes. As shown in Fig. 2, ${ }^{3} \mathrm{H}$-IgM anti-A bound to type $A$ erythrocytes in a dose-dependent manner, while it showed little binding to type B cells $(<10 \%$ of the binding to type A cells). Therefore, any subsequent specific binding of the anti-IgM to these cells reflects almost entirely its interaction with IgM anti-A antibody on the surface of the type A erythrocyte.

Using these erythrocytes, sensitized with known amounts of ${ }^{3} \mathrm{H}$-IgM antibody, we then determined the binding of ${ }^{125} \mathrm{I}$ rabbit IgG anti-human IgM (Fig. 3). Binding of ${ }^{125}$ I anti-IgM to type A erythrocytes varied in proportion to the amount of IgM anti-A on the surface of these cells. In contrast, we observed little binding of ${ }^{125} \mathrm{I}$ anti-IgM to type B cells that were sensitized with ${ }^{3} \mathrm{H}-\mathrm{IgM}$ anti-A, which confirmed our observation that little IgM anti-A bound to type B erythrocytes. The amount of this nonspecific binding of ${ }^{125} \mathrm{I}$ anti-IgM to type B cells was constant and represented a proportionately smaller percentage of the total binding to type A cells as the amount of IgM antibody was increased (Fig. 3). The extent of specific binding of ${ }^{125}$ I anti-IgM to IgM-coated erythrocytes was also determined by preincubating these sensitized cells with a 50-M excess of unlabeled antibody or normal rabbit IgG. The binding of labeled anti-IgM to IgM-sensitized erythrocytes was inhibited $<10 \%$ by the presence of excess normal IgG. In contrast, $>90 \%$ of the binding was inhibited by a similar concentration of unlabeled anti-IgM. These data indicated that the binding of radiolabeled anti-IgM to IgM-coated erythrocytes depends upon the amount of IgM with which these cells are sensitized.

We then determined whether the ${ }^{125} \mathrm{I}$ anti-IgM crossreacted with cell-bound human IgG. Type A erythrocytes were first incubated with increasing amounts of ${ }^{3} \mathrm{H}$-IgM anti-A or ${ }^{3} \mathrm{H}-\mathrm{IgG}$ anti-A, and the amount of cell bound antibody was determined (abscissa, Fig. 4). Using erythrocytes coated with equivalent amounts of ${ }^{3} \mathrm{H}-\mathrm{IgM}$ or ${ }^{3} \mathrm{H}-\mathrm{IgG}$ anti-A, we then measured the binding of ${ }^{125} \mathrm{I}$ anti-IgM. As shown in Fig. 4, there was only a small amount of binding of labeled anti-IgM to erythrocytes that were sensitized with IgG antibody; this cross-reactivity represented $<10 \%$ of the total binding of antiIgM at the levels of IgG and IgM present on ITP platelets (see below).

We then determined the approximate amount of anti-IgM which bound to IgM-coated cells when saturating concentrations of anti-IgM were employed (Fig. 5). Erythrocytes were first sensitized with a concentration of IgM anti-A antibody that

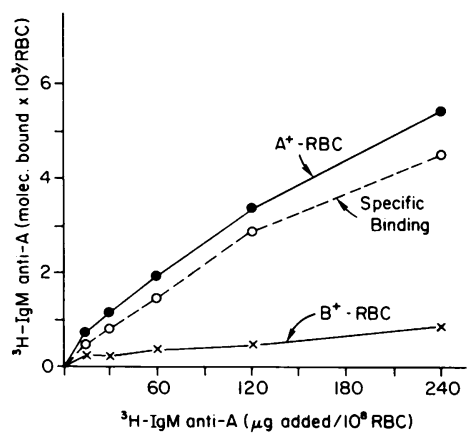

Figure 2. Binding of ${ }^{3} \mathrm{H}-$ IgM anti-A to type $A$ and type B human erythrocytes (RBC). Specific binding represents the difference between ${ }^{3} \mathrm{H}-\mathrm{IgM}$ anti-A binding to each set of erythrocytes (see Methods) 


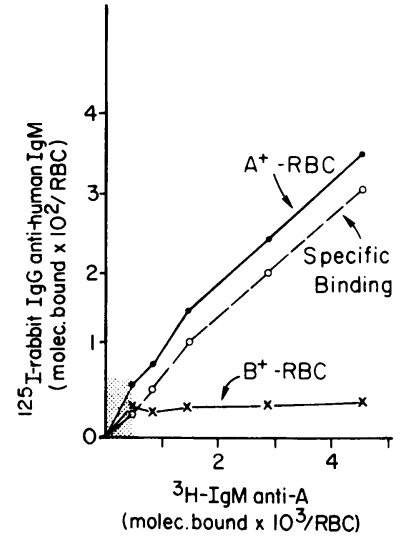

Figure 3. Type A or B erythrocytes $(\mathrm{RBC})$ were sensitized with varying amounts of ${ }^{3} \mathrm{H}-\mathrm{IgM}$ anti-A (abscissa) and the extent of binding of polyclonal ${ }^{125} \mathrm{I}$ anti-IgM was determined (ordinate). The shaded area represents the amount of ${ }^{125} I$ anti-IgM adsorbed to an equivalent number of normal platelets.

was sufficient to bind $\sim 240$ molecules of IgM anti-A per red cell. These cells were then incubated with increasing concentrations of ${ }^{125}$ I IgG anti-IgM and the cell-bound radioactivity was determined. Saturation was achieved when $20 \mu \mathrm{g}$ of antiIgM was added per $10^{8}$ red cells. When these data were analyzed by the method of Scatchard, we found that at saturation approximately one molecule of anti-IgM bound to each molecule of erythrocyte-bound IgM (Fig. 5). Similar results were obtained when these IgM-sensitized cells were incubated with ${ }^{125}$ I monoclonal anti-IgM (not shown). We then compared the binding of the monoclonal and polyclonal anti-IgM reagents using erythrocytes that were sensitized with varying concentrations of IgM antibody. As shown in Figs. 3 and 6 , over the range of IgM found on normal and ITP platelets, approximately the same amount of the ${ }^{125}$ I-labeled polyclonal and monoclonal anti-IgM antibody bound to each molecule of cell-bound IgM. These studies established that these ${ }^{125}$ I anti-IgM reagents primarily detect cell-bound IgM, and that they show little cross-reactivity with IgG antibody on the cell surface.

Binding of ${ }^{125}$ I polyclonal anti-IgM to human platelets. We then studied the binding of radiolabeled anti-IgM to platelets from normal donors and patients with thrombocytopenia. When washed platelets obtained from each of 78 normal individuals were incubated with ${ }^{125} \mathrm{I}$-polyclonal IgG anti-IgM, $0.09 \pm 0.14 \%$ (mean $\pm 2 \mathrm{SD}$ ) of the available radioactivity bound to the cells (Table I, Fig. 7). In contrast, when the same number of normal platelets were incubated with an identical amount of ${ }^{125} \mathrm{I}$-normal rabbit IgG that did not have antiimmunoglobulin activity, $0.04 \pm 0.04 \%$ (mean \pm 2 SD) of the available radioactivity bound to the cells (Table I). This suggested that approximately half of the total binding of the labeled anti-IgM to normal platelets is specific for plateletbound IgM. Similarly, when washed normal platelets were preincubated with a 100 -fold excess of unlabeled normal rabbit

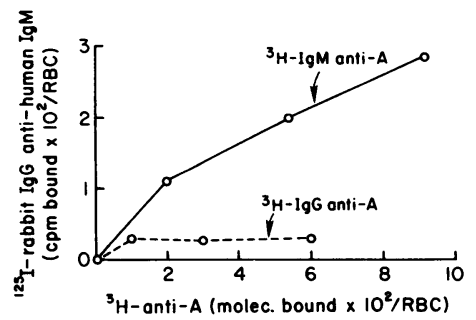

Figure 4. ${ }^{125} \mathrm{I}$ anti-IgM binding to IgM- or IgGcoated erythrocytes (RBC). Type A erythrocytes were sensitized with equivalent amounts (micrograms) of IgG or IgM anti-A antibody before incubation with radiolabeled anti-IgM.

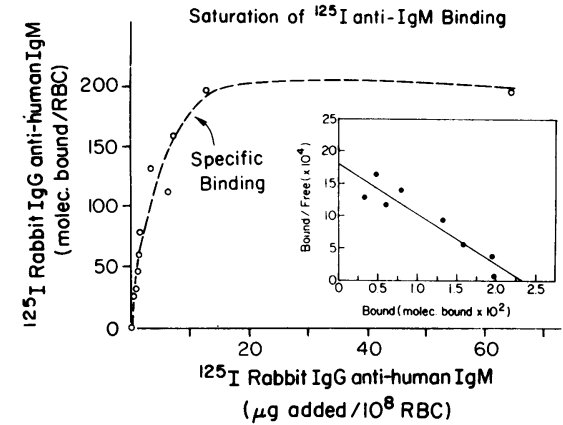

Figure 5. Saturation of ${ }^{125}$ I anti-IgM binding. Erythrocytes (RBC) were sensitized with $\sim 240$ molecules of ${ }^{3} \mathrm{H}$-IgM anti-A/RBC before incubation with increasing amounts of polyclonal ${ }^{125}$ I anti-IgM. The ratio of bound ${ }^{125} \mathrm{I}$ IgG anti-IgM molecules per $\mathrm{RBC}$ to unbound ${ }^{125} \mathrm{I}$ IgG anti-IgM molecules per RBC is shown on the ordinate. The number of molecules of ${ }^{125} \mathrm{I}$ IgG anti-IgM bound per RBC is plotted on the abscissa. The insert depicts a Scatchard plot of the data. The $X$ intercept (234 sites) indicates the number of IgG anti-IgM binding sites at saturation.

IgG, the binding of labeled IgG anti-IgM to platelets was reduced by $\sim 40 \%$; in contrast, $>90 \%$ of the binding of labeled anti-IgM to normal platelets was prevented by the presence of a 100-fold excess of unlabeled anti-IgM. Therefore, these studies suggest that small but detectable amounts of IgM are present on the surface of normal washed platelets. This amount of ${ }^{125} \mathrm{I}$ anti-IgM which binds to normal platelets is equivalent to that bound to erythrocytes coated with 100-400 molecules of ${ }^{3} \mathrm{H}$-IgM per cell (shaded area, Fig. 3).

We then studied the binding of ${ }^{125}$ I anti-IgM to platelets obtained from 127 patients who had a clinical diagnosis of ITP (Table I, Fig. 7). The platelets of these patients bound $0.28 \pm 0.41 \%$ (mean $\pm 2 \mathrm{SD}$ ) of the total available radioactivity (Table I, Fig. 7). The platelets from 66 of these 127 patients (52\%) showed an increase in the binding of ${ }^{125} \mathrm{I}$ anti-IgM, which was $>2$ SD from the mean value of the normal population; platelets from 43 patients bound anti-IgM in excess of $3 \mathrm{SD}$ from the mean. In contrast, the binding of normal rabbit IgG by ITP platelets was essentially identical to its binding by normal platelets (Table I). We also studied the platelets from two patients with Waldenstrom's macroglobulinemia who had serum concentrations of IgM of 2.5 and 2.8 $\mathrm{g} / \mathrm{dl}$ and who had platelet counts of $80,000 / \mathrm{mm}^{3}$ and $120,000 /$ $\mathrm{mm}^{3}$, respectively. In both cases, platelet-IgM fell within the normal range. Platelets from only 4 of 32 patients with thrombocytopenia, who did not have a clinical diagnosis of ITP, bound increased amounts of anti-IgM (Fig. 7, Table I). Two of these four had demonstrable drug-dependent (gold,

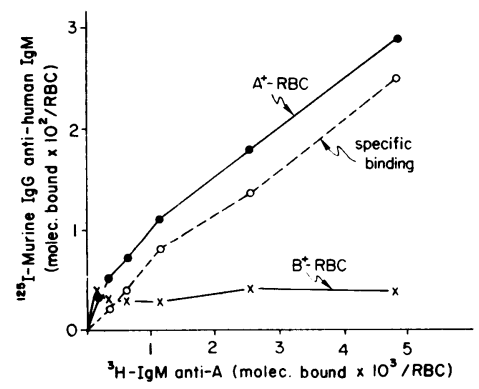

Figure 6. Monoclonal ${ }^{125}$ I anti-IgM binding to IgMcoated erythrocytes (RBC). Experimental conditions are identical to those in Fig. 3. 
Table I. Binding of Polyclonal ${ }^{125}$ I-Rabbit IgG Anti-Human Antibodies to Platelets

\begin{tabular}{lllll}
\hline & \multicolumn{2}{c}{ \% Binding } & & \\
\cline { 2 - 5 } & Anti-IgM & Anti-IgG & Anti-C3 & $\begin{array}{l}\text { Normal } \\
\text { IgG* }\end{array}$ \\
\hline & & & & \\
\hline $\begin{array}{l}\text { Source of platelets } \\
\text { Normals }(n=78)\end{array}$ & $0.09 \pm 0.14 \ddagger$ & $0.08 \pm 0.10$ & $0.16 \pm 0.14$ & $0.04 \pm 0.04$ \\
$\begin{array}{l}\text { ITP }(n=127) \\
\text { Thrombocytopenic } \\
\text { controls } \\
(n=32)\end{array}$ & $0.28 \pm 0.41$ & $0.39 \pm 0.78$ & $0.38 \pm 0.41$ & $0.05 \pm 0.05$ \\
& $0.13 \pm 0.20$ & $0.14 \pm 0.22$ & $0.23 \pm 0.21$ & $0.03 \pm 0.04$
\end{tabular}

* ${ }^{125}$ I-labeled normal rabbit IgG.

‡ Platelet-bound radioactivity (mean $\pm 2 \mathrm{SD}$ ) expressed as a percentage of the total available radioactivity.

heparin) antibodies. The level of binding of anti-IgM to platelets from the thrombocytopenic control population as a whole did not differ significantly from the level found in the normal population $(P>0.05)$. In contrast, the binding of ${ }^{125} I$ anti-IgM to platelets from patients with ITP was statistically significantly different from both the normal control population and the thrombocytopenic control population at both $2 \mathrm{SD}$ and $3 \mathrm{SD}$ from the mean $(P<0.001)$.

Comparative binding of ${ }^{125} \mathrm{I}$ anti-C3 and ${ }^{125} \mathrm{I}$ anti-IgM to ITP platelets. We then studied the relationship between the extent of binding of anti-C3 and the amount of PA-IgM and PA-IgG present in our patients with ITP. As shown in Table II, our patients commonly had increased levels of all three proteins. The platelets from 54 of 66 patients which bound increased amounts of anti-IgM also bound increased amounts of anti-C3. In contrast, the platelets from 46 of the 61 patients

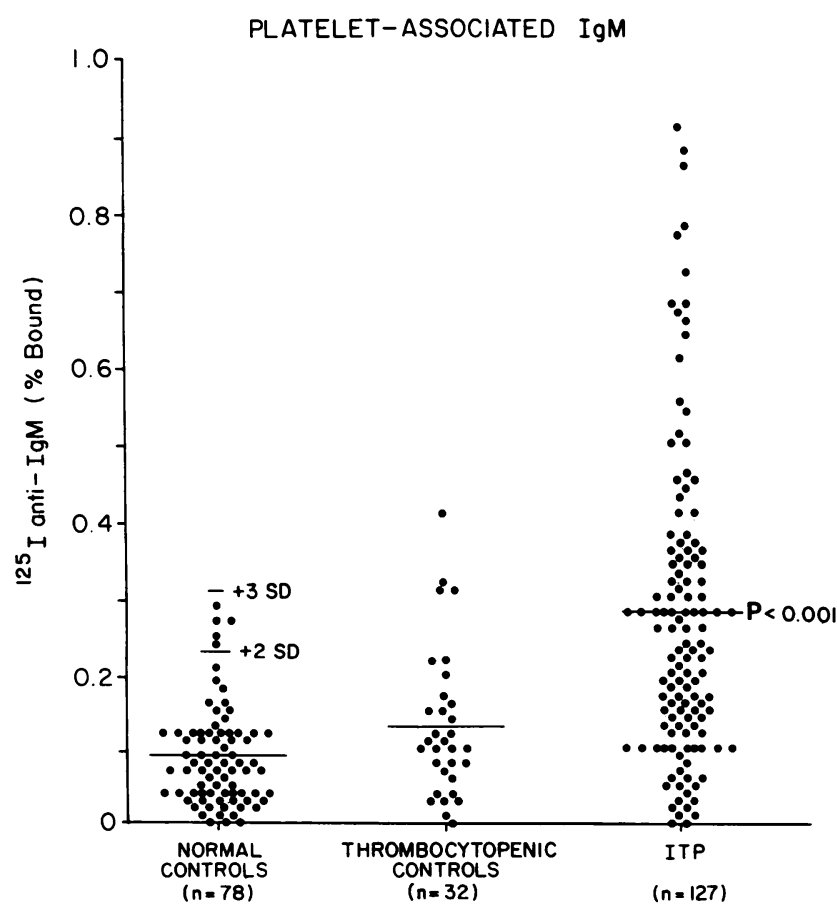

Figure 7. Platelet-associated IgM in normal controls, thrombocytopenic controls, and patients with ITP.
Table II. Platelet-associated $C 3$ in ITP

\begin{tabular}{lll}
\hline & $\begin{array}{l}\text { Increased PA-C3 } \\
(69)\end{array}$ & $\begin{array}{l}\text { Normal PA-C3 } \\
(58)\end{array}$ \\
\hline $1 \begin{array}{c}\text { Increased PA-IgM } \\
\text { only (>2 SD) } \\
\text { Increased PA-IgM } \\
\text { only (>3 SD) }\end{array}$ & 12 & 7 \\
$2 \begin{array}{c}\text { Increased PA-IgM and } \\
\text { increased PA-IgG }\end{array}$ & 42 & 2 \\
$\begin{array}{c}3 \text { Increased PA-IgG } \\
\text { only }\end{array}$ & 9 & 5 \\
$4 \begin{array}{c}\text { Normal PA-IgM and } \\
\text { normal PA-IgG }\end{array}$ & 6 & 17 \\
\hline
\end{tabular}

which bound normal amounts of anti-IgM also bound normal amounts of anti-C3 $(P<0.001)$. In the subset of patients having a PA-IgM determination $>3$ SD from the mean, the platelets from 39 of these 41 individuals also had increased levels of PA-C3. Furthermore, we observed a relationship between the level of PA-IgM and PA-C3 in these 127 patients with ITP $(P<0.01, r=0.53$, Fig. 8). This positive relationship between PA-IgM and PA-C3 was noted in patients with clinically active or inactive ITP, in patients before or after splenectomy, and in patients who were receiving corticosteroids as well as those who were untreated at the time of study. In contrast to the relationship between PA-IgM and PA-C3, an isolated increase in PA-IgG with a concomitant increase in PA-C3 was observed in only 9 of 38 cases. Moreover, we observed only a moderate correlation $(P=0.04)$ between the presence of increased PA-IgG, as an independent variable, and the presence of increased PA-C3.

We did not observe a statistically significant relationship between the level of PA-IgM and PA-IgG. In addition, 17 patients, representing $13 \%$ of the total ITP population studied, had normal values for PA-IgG, PA-IgM, and PA-C3. 10 of these patients were in clinical remission at the time of study; an additional 3 patients had been started on corticosteroids within $72 \mathrm{~h}$ of the time of study.

Comparative binding of polyclonal and monoclonal antiIgM to platelets. Recent studies indicate that monoclonal

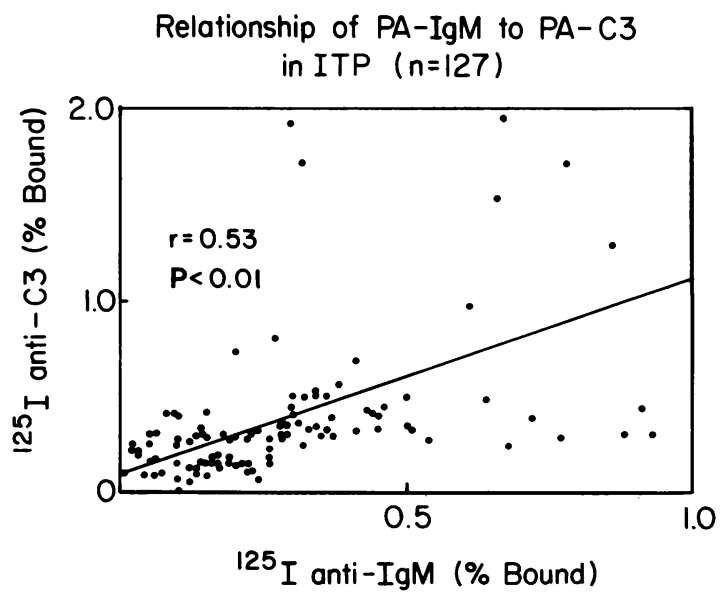

Figure 8. Relationship of PA-IgM to PA-C3 in ITP. 
antibodies which detect human immunoglobulins show less nonspecific binding to the platelet surface than polyclonal reagents; thus, these reagents may show greater specific binding to their cell-bound ligand $(28,29)$. We, therefore, compared the binding of polyclonal and monoclonal anti-IgM antibodies with platelets from a second consecutive series of 35 normal volunteers, 48 patients with ITP and 12 thrombocytopenic patients who did not have ITP. We observed that platelets from normal individuals bound approximately the same amount of the monoclonal and polyclonal antibodies (Table III). In addition, platelets from each of 12 thrombocytopenic patients who did not have ITP bound amounts of monoclonal anti-IgM which fell within the normal range. Platelets from 35 of 48 ITP patients bound an increased amount of polyclonal anti-IgM and 30 of 48 bound an increased amount of monoclonal anti-IgM. There was strong concordance between positive tests and negative tests when the platelets of the same individuals were studied using both reagents $(P<0.05)$. We also observed a positive correlation between the extent of binding of each labeled antibody to ITP platelets ( $r=0.79$, Fig. 9). However, platelets from 5 ITP patients which bound significantly increased amounts of polyclonal anti-IgM bound amounts of monoclonal anti-IgM which clearly fell within the normal range. In two cases, we noted a borderline elevation in the binding of the monoclonal reagent that was associated with a normal level of binding of polyclonal anti-IgM (Fig. 9).

Presence of IgM anti-platelet antibodies in ITP plasma. These findings suggest that increased amounts of IgM are often present on ITP platelets. The data also suggest that IgM antiplatelet antibody may initiate binding of $\mathrm{C} 3$ to the platelet surface. We, therefore, sought to determine directly if warmreacting IgM anti-platelet antibodies were present in the plasma of some patients with ITP and whether they activated complement.

We studied the plasmas from four patients with ITP who had increased levels of platelet-associated IgM. The plasmas from two of these four patients placed increased amounts of IgM onto normal platelets $\left(1.28\right.$ and $1.43 \%$ binding of ${ }^{125} \mathrm{I}$ anti-IgM) when compared with normal plasma $(0.40 \pm 0.38 \%$ binding of ${ }^{125}$ I anti-IgM) (mean $\pm 2 \mathrm{SD}, n=53$ ). These two patient plasmas and the IgM fractions isolated from them also caused $\mathrm{C} 3$ consumption, as assessed by effective molecule titration (not shown), and the deposition of ${ }^{3} \mathrm{H}-\mathrm{C} 3$ onto the platelet surface (Table IV). These IgM fractions did not contain IgG that was detectable by Ouchterlony analysis. The ability of these IgM proteins to place ${ }^{3} \mathrm{H}-\mathrm{C} 3$ on normal platelets was not diminished after incubation with an anti-IgG immunoadsorbent capable of binding $2 \mathrm{mg}$ of $\mathrm{IgG}$. The $\mathrm{IgG}$ fraction

Table III. Binding of Polyclonal and Monoclonal ${ }^{125}$ I Anti-IgM to Platelets

\begin{tabular}{lll}
\hline & $\begin{array}{l}\text { 125I-Polyclonal } \\
\text { anti-IgM }\end{array}$ & $\begin{array}{l}\text { 125I-Monoclonal } \\
\text { anti-IgM }\end{array}$ \\
\hline $\begin{array}{l}\text { Source of platelets } \\
\quad \text { Normals }(n=35)\end{array}$ & $0.06 \pm 0.07^{*}$ & $0.05 \pm 0.06$ \\
$\quad$ ITP $(n=48)$ & $0.32 \pm 0.34$ & $0.21 \pm 0.34$ \\
$\quad \begin{array}{l}\text { Thrombocytopenic } \\
\text { controls }(n=12)\end{array}$ & $0.08 \pm 0.09$ & $0.06 \pm 0.08$ \\
\hline
\end{tabular}

* Platelet-bound radioactivity (mean $\pm 2 \mathrm{SD}$ ) expressed as a percentage of the total available radioactivity.

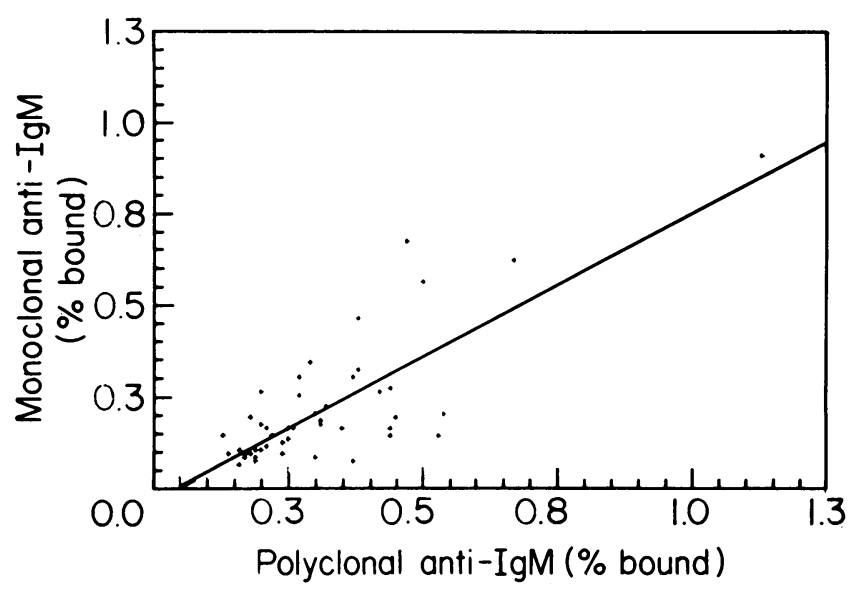

Figure 9. Relationship between the percentage of binding of ${ }^{125} \mathrm{I}$ polyclonal (rabbit) anti-IgM, and ${ }^{125}$ I-monoclonal (murine) anti-IgM to platelets from patients with ITP.

isolated from a patient with anti-Pl ${ }^{\mathrm{A} 1}$ antibody also caused platelet C3 deposition as previously reported (27).

\section{Discussion}

It is generally accepted that the platelets from most patients with ITP have increased levels of IgG on their surface. The platelets of some ITP patients have increased levels of C3 as well. Several investigators have observed that the platelets from a subset of ITP patients have increased C3 on their surface without a detectable increase in IgG. Since this increased $\mathrm{C} 3$ on the platelet surface may have been caused by complement activation initiated by another class of antibody, we examined the level of PA-IgM on ITP platelets.

We first established the integrity of our radiolabeled IgG anti-IgM antibody using human erythrocytes that were quantitatively coated with ${ }^{3} \mathrm{H}-\mathrm{IgM}$ anti-A. We found that we could detect the binding of labeled anti-IgM to as few as $50 \mathrm{IgM}$ anti-A molecules on the surface of the erythrocyte, and that

Table IV. C3 Binding to Platelets Caused by IgM Anti-Platelet Antibody in ITP Plasma

\begin{tabular}{lcc}
\hline & $\begin{array}{l}\text { Anti-platelet } \\
\text { antibody }\end{array}$ & Platelet C3 deposition \\
\hline & $\mu g / m l$ & $C 3$ molecules/platelet \\
Patient 1 & 300 & 3,500 \\
$\quad$ IgM fraction & 150 & 1,900 \\
Patient 2 & 190 & 6,400 \\
$\quad$ IgM fraction & 80 & 3,200 \\
IgG fraction & 140 & $<500$ \\
IgM fraction adsorbed with & & \\
$\quad$ anti-IgG & 80 & 3,000 \\
Anti-PI ${ }^{\text {Al }}$ antibody, IgG fraction & 210 & 15,900 \\
$\quad 105$ & 4,600 \\
$\quad$ Normal donors $(n=5)$, IgM & & \\
$\quad$ fraction & 300 & $<500$
\end{tabular}

Gel filtered platelets were incubated in the presence of a source of antibody and autologous plasma containing ${ }^{3} \mathrm{H}-\mathrm{C} 3$ as a source of complement. In the absence of antibody $<500$ molecules of $\mathrm{C} 3$ bound per platelet. 
saturable binding of the ${ }^{125}$ I anti-IgM to IgM-coated cells could be demonstrated. Moreover, labeled anti-IgM showed minimal binding to IgG-coated erythrocytes. We then studied the binding of ${ }^{125} \mathrm{I}$ anti-IgM to human platelets. Since the stoichiometry of binding of the labeled anti-IgM to platelet-bound IgM is unknown, we expressed our data in terms of the percentage of labeled anti-IgM that bound to normal or patient platelets. We observed that platelets from normal individuals bound more ${ }^{125} \mathrm{I}-\mathrm{IgG}$ anti-IgM than an equivalent amount of control ${ }^{125} \mathrm{I}-\mathrm{IgG}$, which was consistent with a low level of IgM on the normal platelet surface. Furthermore, platelets from 50 to $60 \%$ of patients with ITP had increased levels of IgM on their surface compared with normal platelets. The increase in platelet IgM was generally associated with increased levels of platelet C3. This relationship between platelet IgM and platelet C3 was noted in patients with ITP irrespective of their platelet count and in patients who were receiving corticosteroids, as well as in those who had previously undergone splenectomy. Therefore, the previously reported association between the level of platelet IgG and platelet $\mathrm{C} 3(12,14,16,30)$ could be mediated in some cases by the concurrent presence of IgM anti-platelet antibodies.

There is wide variation in the reported incidence of such IgM antibodies in ITP and other platelet disorders. There is also little agreement as to the level of IgM on platelets (1522). However, our work is in accord with that of several groups of investigators who observed, using a variety of techniques, that many patients with active ITP have increased amounts of IgM on their platelets $(16,10,22)$. The variation in the incidence of increased platelet-bound IgM may reflect either differences in the sensitivity of the assay systems or differences in the patient populations in which the measurements were made.

The enhanced binding of anti-IgM to ITP platelets, which we and others have observed, is most likely due to the presence of IgM anti-platelet antibodies and is not the result of an in vitro artifact for two reasons. First, the increased binding of anti-IgM to ITP platelets was not due to enhanced binding of the radiolabeled ligand itself. ITP platelets did not bind equivalent amounts of radiolabeled antibodies that recognize IgM, IgG, and C3. Second, ITP platelets bound an amount of labeled normal rabbit IgG which was essentially identical to the amount that bound to normal platelets.

It is also unlikely that our finding of increased IgM on ITP platelets is due solely to nonspecific adsorption of serum proteins or particulate matter to ITP platelets in vivo $(8,9$, $31,32)$. The level of platelet IgM present on ITP platelets appears comparable to the amount of platelet-bound $\mathrm{IgG}$, although the serum concentration of IgM is $\sim 1 / 10$ that of IgG. Second, using a polyclonal anti-IgM reagent, we did not observe an elevation in platelet-IgM in the two patients we studied who had a high concentration of $\operatorname{IgM}$ paraprotein in their sera. In addition, we found a strong correlation between the amount of IgM on ITP platelets and the amount of C3 on ITP platelets; similar correlations were not as pronounced between PA-IgG and either platelet-IgM or platelet-C3. This finding suggests that $\mathrm{C} 3$ is present on the platelet because complement was activated by IgM which bound to the platelet either as anti-platelet antibody or as part of an immune complex. Finally, we directly demonstrated the presence of warm reacting, complement-fixing IgM anti-platelet antibodies in the plasma of two patients with ITP.
We also studied the possibility that recently developed monoclonal antibodies to human immunoglobulins might prove to be superior reagents for the detection of increased PA-IgM because of their lower nonspecific binding to cell surfaces $(28,29)$. However, our use of a monoclonal antiglobulin reagent did not enhance the clinical sensitivity of this radioimmunoassay as applied to measurement of PA-IgM. Although a good correlation was found between the polyclonal and monoclonal ligands, in several cases increased IgM was detected only with the polyclonal reagent (Fig. 9). The reason for this result is uncertain. Allotypic restriction has been described among autoantibodies in autoimmune hemolytic anemia and other disorders (33). It is not known whether there are similar antigenic restrictions among autoreactive antiplatelet antibodies and if the epitope recognized by some monoclonal anti-IgM antibodies is uniformly present on all IgM anti-platelet antibodies.

In this entire series, increased PA-IgM was found on the platelets of only 4 of 44 thrombocytopenic patients who did not have ITP; in two patients, drug-dependent thrombocytopenia was suspected which, in fact, may have been mediated by anti-platelet antibody. Therefore, the finding of increased amounts of platelet-bound IgM on ITP platelets in this study appears to be a less sensitive, but a more specific serologic marker for ITP than is the finding of increased platelet-IgG (Fig. 7). This may reflect the lower serum concentrations of IgM as compared with IgG, the lack of a receptor on platelets for the heavy chain of the IgM molecule, or possibly the transient nature of IgM antibody production to most platelet antigens. Studies in other patient populations, such as additional patients with IgM paraproteinemia, may define other circumstances in which increased amounts of PA-IgM are present.

The finding of warm-reacting IgM antibodies in ITP plasma was surprising, and differs from the reported findings in autoimmune hemolytic anemia. The antigen recognized by the IgM antiplatelet antibodies is unknown. The results of recent studies indicate that some IgG autoantibodies in ITP may be directed at determinants on glycoproteins IIb and IIIa (34-36). It will be of interest to determine whether similar antigens are recognized by IgM antibodies. Alternatively, some investigators have suggested that the IgM antibodies may recognize allotypic or idiotypic portions of the platelet-bound IgG molecule itself (20). Additional study will be required to identify the antigen(s) recognized by these antibodies.

Finally, we asked whether the presence of IgM antibody was more likely to occur in certain clinically distinct subgroups of patients with ITP or whether PA-IgM played a role in the clinical course and management of this disease. It is possible, for example, that IgM antibodies directly injure platelets, and lead to their removal by nonimmunologic mechanisms. In agreement with other groups of investigators, we found a complex immunologic profile on ITP platelets (Table II). However, we did not observe a relationship between the level of PA-IgM, as an independent variable, and the platelet count. In part, this may relate to the heterogeneous population studied, which included adults and children, acute and chronic ITP, and both newly diagnosed and heavily treated patients. In part, this may also reflect the fact that the platelet count is a dynamic value that is dependent upon antibody titer and class, efficiency of clearance by the phagocytic system, and extent of marrow production. Binding of $\mathrm{C} 3$ to erythrocytes, initiated by IgM antibodies, plays a major role in the site and 
rate of removal of these cells from the circulation. However, a larger prospective study of a more homogeneous patient population will be needed to determine whether the presence of IgM and C3 on platelets is an important determinant of platelet count, platelet function, site of sequestration, or response to therapy in ITP.

\section{Acknowledgments}

We thank Mrs. Diane Tate and Mrs. Patricia Lafferty for preparing this manuscript for publication.

This work was supported by National Institutes of Health (NIH) grants HL-28207 and HL-27068. Dr. Cines is the recipient of a NIH Research Career Development Award 1KO4-HL-00956.

\section{References}

1. Dixon, R., W. Rosse, and L. Ebbert. 1975. Quantitative determination of antibody in idiopathic thrombocytopenic purpura. Correlation of serum and platelet-bound antibody with clinical response. N. Engl. J. Med. 292:230-236.

2. Mueller-Eckhardt, C., W. Kayser, K. Mersch-Baumert, G. Mueller-Eckhardt, M. Breidenbach, and M. Graubner. 1980. The clinical significance of platelet-associated IgG: a study of 298 patients with various disorders. Br. J. Haematol. 46:123-131.

3. Mueller-Eckhardt, C., G. Mueller-Eckhardt, W. Kayser, R. M. Voss, J. Wegner, and E. Kuenzlin. 1982. Platelet-associated IgG, platelet survival, and platelet sequestration in thrombocytopenic states. Br. J. Haematol. 52:49-58.

4. Lightsey, A. L., Jr., H. M. Koenig, R. McMillan, and J. R. Stone, Jr. 1979. Platelet-associated immunoglobulin $\mathrm{G}$ in childhood idiopathic thrombocytopenic purpura. J. Pediatr. 94:201-204.

5. Kernoff, L. M., and E. Malan. 1983. Platelet antibody levels do not correlate with response to therapy in idiopathic thrombocytopenic purpura. Br. J. Haematol. 53:559-562.

6. Shaw, G. M., J. Axelson, J. G. Maglott, and A. LoBuglio. 1984. Quantitation of platelet-bound IgG by ${ }^{125}$ I-staphylococcal Protein A in immune thrombocytopenic purpura and other thrombocytopenic disorders. Blood. 63:154-161.

7. Cheung, N.-K., M. W. Hilgartner, I. Schulman, P. McFall, and B. E. Glader. 1983. Platelet-associated immunoglobulin $G$ in childhood idiopathic thrombocytopenic purpura. J. Pediatr. 102:366-370.

8. McGrath, K. M., J. J. Stuart, and F. Richards. 1979. Correlation between serum IgG, platelet membrane IgG and platelet function in hypergammaglobulinemic states. Br. J. Haematol. 42:585-591.

9. Pfueller, S. L., L. Cosgrove, B. G. Firkin, and D. Tew. 1981. Relationship of raised platelet IgG in thrombocytopenia to total platelet protein content. Br. J. Haematol. 49:293-302.

10. Kelton, J. G., P. J. Powers, and C. J. Carter. 1982. A prospective study on the measurement of platelet-associated IgG for the diagnosis of idiopathic thrombocytopenic purpura. Blood. 60:1050-1053.

11. Schreiber, A. D., and M. M. Frank. 1972. Role of antibody and complement in the immune clearance and destruction of erythrocytes. I. In vivo effects of IgG and IgM complement-fixing sites. $J$. Clin. Invest. 51:575-582.

12. Hauch, T. W., and W. F. Rosse. 1977. Platelet-bound complement (C3) in immune thrombocytopenia. Blood. 50:1129-1136.

13. Cines, D. B., and A. D. Schreiber. 1979. Immune thrombocytopenia: use of a Coombs antiglobulin test to detect IgG and C3 on platelets. N. Engl. J. Med. 300:106-111.

14. Myers, T. J., B. K. Kim, M. Steiner, and M. G. Baldini. 1982. Platelet-associated complement $\mathrm{C} 3$ in immune thrombocyotpenic purpura. Blood. 59:1023-1028.

15. Follea, G., B. Mandrand, and M. Dechavanne. 1982. Simultaneous enzyme-immunologic assays of platelet-associated IgG, IgM and C3. A useful tool in assessment of immune thrombocytopenias. Thromb. Res. 26:249-258.
16. Winiarski, J., and G. Holm. 1983. Platelet-associated immunoglobulins and complement in idiopathic thrombocytopenic purpura. Clin. Exp. Immunol. 53:201-207.

17. Van Boxtel, C. J., F. Oosterhof, and C. P. Engelfreit. 1975. Immunofluorescence microphotometry for the detection of platelet antibodies. III. Demonstration of autoantibodies against platelets. Scand. J. Immunol. 4:657-672.

18. Veenhoven, W. A., G. S. Van der Schans, and H. O. Niewis. 1980. Platelet antibodies in idiopathic thrombocytopenic purpura. Clin. Exp. Immunol. 39:645-651.

19. Von dem Borne, A. E. G. Kr., F. M. Helmerhorst, E. F. Van Leeuwen, H. G. Pegels, E. von Riesz, and C. P. Engelfriet. 1980. Autoimmune thrombocytopenia: detection of platelet autoantibodies with the suspension immunofluorescence test. Br. J. Haematol. 45: 319-327.

20. Nel, J. O., K. Stevens, A. Mouton, and F. J. Pretorius. 1983. Platelet-bound IgM in autoimmune thrombocytopenia. Blood. 61:119124.

21. Pawha, J., D. Giuliani, and B. S. Morse. 1983. Plateletassociated IgM levels in thrombocytopenia. Vox Sang. 45:97-103.

22. Bussel, J. B., R. P. Kimberly, I. Schulman, C. CunninghamRundles, N. Cheung, E. M. Smithwick, J. O'Malley, S. Barandun, and M. W. Hilgartner. 1983. Intravenous gammaglobulin treatment of chronic idiopathic thrombocytopenic purpura. Blood. 62:480-486.

23. McConahey, P. J., and F. J. Dixon. 1966. A method of trace iodination of proteins for immunologic studies. Int. Arch. Allergy Appl. Immunol. 29:185-189.

24. Lowry, O. H., N. J. Rosebrough, A. L. Farr, and R. J. Randall. 1951. Protein measurement with the Folin phenol reagent. J. Biol. Chem. 193:265-275.

25. Dodge, J. T., C. Mitchell, and D. J. Hanahan. 1983. The preparation and chemical characteristics of hemoglobin-free ghosts of human erythrocytes. Arch. Biochem. Biophys. 100:119-130.

26. Hammer, C. H., G. H. Wirtz, L. Renfer, H. D. Gresham, and B. F. Tack. 1981. Large scale isolation of functionally active components of the human complement system. J. Biol. Chem. 256:3995-4006.

27. Cines, D. B., and A. D. Schreiber. 1979. Effect of anti-PIAI antibody on human platelets. I. The role of complement. Blood. 53: 567-577.

28. LoBuglio, A. F., W. S. Court, L. Vinocur, G. Maglott, and G. M. Shaw. 1983. Immune thrombocytopenic purpura. Use of a ${ }^{125}$ Ilabeled antihuman IgG monoclonal antibody to quantify plateletbound IgG. $N$. Engl. J. Med. 309:459-463.

29. Rosse, W. F., D. V. Devine, and R. Ware. 1984. Reactions of immunoglobulin $\mathrm{G}$ binding ligands with platelets and platelet-associated immunoglobulin G. J. Clin. Invest. 73:489-496.

30. Kayser, W., C. Mueller-Eckhardt, S. Bhakdi, and K. Ebert. 1983. Platelet-associated complement $\mathrm{C} 3$ in thrombocytopenic states. Br. J. Haematol.

31. Kelton, J. G., and K. Steeves. 1983. The amount of plateletbound albumin parallels the amount of IgG on washed platelets from patients with immune thrombocytopenia. Blood. 62:924-927.

32. Shulman, N. R., C. A. Leissinger, A. Hutchkiss, and C. Katz. 1982. An in vivo model demonstrating that elevated platelet-associated IgG is a nonspecific consequence of platelet destruction. Blood. 60(s): 191a. (Abstr.)

33. Litwin, S. D., S. Balaban, and M. E. Eyster. 1973. Gm allotype preference in erythrocyte IgG antibodies of patients with autoimmune hemolytic anemia. Blood. 42:241-246.

34. Van Leeuwen, E. F., J. Th. M. van der Ven, and A. E. G. Kr. Von dem Borne. 1982. Specificity of autoantibodies in autoimmune thrombocytopenia. Blood. 59:23-26.

35. Varon, D., and S. Karpatkin. 1983. A monoclonal platelet antibody with decreased reactivity for autoimmune thrombocytopenic platelets. Proc. Natl. Acad. Sci. USA. 80:6992-6995.

36. Woods, V. L., Jr., E. H. Oh, D. Mason, and R. McMillan. 1984. Autoantibodies against the platelet glycoprotein IIb/IIIa complex in patients with chronic ITP. Blood. 63:368-375. 